\title{
THE EFFECTS OF FATIGUE AND THE POST-CONCUSSION SYNDROME ON EXECUTIVE FUNCTIONING IN TRAUMATIC BRAIN INJURY AND HEALTHY COMPARISONS
}

\author{
Authors: \\ Jessica D. Fry ${ }^{1}$ \\ Kirston Greenop ${ }^{1}$ \\ Enid Schutte ${ }^{1}$ \\ Affiliations: \\ ${ }^{1}$ Department of \\ Psychology, University \\ of the Witwatersrand, \\ South Africa \\ Correspondence to:
Jessica Fry \\ email: \\ jessica.fry@hotmail.com

\section{Postal address:} \\ Department of Psychology, \\ School of Human and \\ Community Development, \\ University of the \\ Witwatersrand, Private Bag \\ X3, Johannesburg 2050, \\ South Africa
}

\section{Keywords:}

behavioural manifestations; head injury; perseveration; rehabilitation efforts; Wisconsin Card Sorting Test

\section{Dates:}

Received: 18 Feb. 2010

Accepted: 08 June 2010

Published: 09 Nov. 2010

How to cite this article: Fry, J.D., Greenop, K., Schutte, E. 'The effects of fatigue and the postconcussion syndrome on executive functioning in traumatic brain injury and healthy comparisons', Health SA Gesondheid 15(1), Art. \#541, 8 pages. DOI: $10.4102 /$ hsag. v15i1.541

This article is available at:

http:/ / www.hsag.co.za

(C) 2010. The Authors. Licensee: OpenJournals Publishing. This work is licensed under the Creative Commons

\section{ABSTRACT}

In this study, behavioural manifestations of compromised executive control, including perseveration and reduced inductive reasoning, on the Wisconsin Card Sorting Test (WCST) were investigated. Performance was affected by fatigue in both a head-injured and matched population, which has implications for health care professionals involved in rehabilitation and assessment. A fatigue condition was manipulated for 15 moderate to severe traumatic brain injury (TBI) individuals through the course of a three-hour neuropsychological testing session. A comparison sample of 15 participants in a group of 'no history of TBI' was fatigued through the same approach. All fatigued participants (with and without TBI) displayed trends towards increased levels of perseveration and reduced inductive reasoning on the WCST. Thus, the effects of fatigue on high-level functioning are pervasive even when not head-injured. This finding supports the sub-optimal performance in cognitive skills, specifically in executive control, that is often found in fatigued people. These findings are relevant for the manner in which rehabilitation interventions and medico-legal assessments are structured. Importantly, the order of tests, their interpretation and rest sessions should be clearly indicated and interpreted in assessment reports and rehabilitation sessions.

\section{OPSOMMING}

In hierdie studie is gedragsmanifestering in individue met gekompromitteerde uitvoerende funksionering, met inbegrip van perseverasie en verminderde induktiewe redenering, op die Wisconsin-kaartsorteringstoets (WCST), bestudeer. Die waarneming dat prestasie deur uitputting beïnvloed word in sowel normale populasies as dié met kopbeserings het implikasies vir gesondheidsorgpersoneel wat by rehabilitasie en assessering betrokke is. ' $n$ Uitputtingstoestand is gemanipuleer vir 15 matig ernstige individue met traumatiese kopbeserings (TKB) vir die duur van 'n drie uur lange toetssessie. 'n Vergelykingsmonster van 15 deelnemers met geen geskiedenis van kopbeserings is deur dieselfde metodologie uitgeput. Alle uitgeputte deelnemers (met en sonder TKB) het ' $n$ neiging na verhoogde vlakke van perseverasie en verminderde induktiewe redenering op die WCST getoon. Die impak van uitputting op hoëvlak-funksionering is dus verreikend, selfs in gevalle waar geen kopbesering opgedoen is nie. Die bevinding ondersteun suboptimale prestasie in kognitiewe vaardighede, en spesifiek in uitvoerende beheer, wat dikwels onder uitgeputte mense gevind word. Hierdie bevindinge is van belang vir die manier waarop rehabilitasie-intervensies en regsgeneeskundige assesserings gestruktureer word. Die volgorde van toetse, die interpretasie daarvan en die rusperiodes moet duidelik in assesseringsverslae en rehabilitasiesessies aangetoon en geïnterpreteer word.

\section{INTRODUCTION}

Specific head injuries can result in compromised executive control, which may manifest as decreased mental flexibility when participants complete complex tasks such as planning, handling multiple sources of information and making decisions. In addition, fatigue is a common consequence of certain head injuries and is exacerbated by life tasks and demands. Van der Linden, Frese and Meijman (2003) investigated the general effects of fatigue on executive functioning using the Wisconsin Card Sorting Test (WCST) (Berg 1948; Grant \& Berg 1948), which measures cognitive flexibility. They found that fatigued traumatic brain injury (TBI) patients evidenced more perseveration when compared to a non-fatigued group. This compromised executive control under conditions of fatigue may explain the typical errors and sub-optimal performance that are often found in fatigued people, such as reduced critical thinking ability after an arduous work day (Van der Linden, Frese \& Meijman 2003).

\section{Background to the study}

TBI has been defined as 'any brain damage, even trifling, related to an impact on the brain' (Belmont et al. 2006:370) that may cause substantial disability and morbidity and it occurs when sudden trauma damages the brain and disrupts normal brain function. Diffuse axonal injury is one of the most common and important pathologic features of TBI, constituting mostly microscopic damage that often disrupts normal neuronal functioning (Smith, Meaney \& Shull 2003). This may result in disruptions of optimal cognitive functioning, including executive dysfunction, as well as memory and attention deficits.

As a result of the slowed processing resulting from many microscopic sites of diffusely distributed damage, activities that were automatic may now only be accomplished with deliberate effort, which is further fatiguing. Activities that are performed frequently during the day, such as concentrating, warding off distractions, monitoring ongoing performances and planning, may become effortful (Ponsford \& Kinsella 1992). To compound matters, as individuals become fatigued, their efficiency levels plummet, so that activities that were difficult when they were rested become extremely laboured and more error-prone (Ponsford \& Kinsella 1992). 
Fatigue is the conscious, decreased ability for physical and/or mental activity due to an imbalance in the availability, utilisation or retrieval of the physiological and/or psychological resources required to perform the activity (Aaronson et al. 1999). Fatigue is a common and frequently disabling symptom in patients with TBI, regardless of severity. Internationally, it is present in $43 \%$ to $73 \%$ of patients in primary care (Olver, Ponsford \& Curran 1996; Van der Naalt et al. 1999) and remains in a vast majority of patients 5 years post-injury - fatigue and mental effort have been found to be poorly correlated with time since injury (Olver et al. 1996) or with injury severity (Belmont et al. 2006). Fatigue often represents a permanent alteration in the patient's functioning.

Executive functions are often affected after moderate and severe TBI (Zillmer \& Spiers 2001). Dysexecutive difficulties, with their behavioural and attentional constituents, are characterised by an inability to formulate plans and to undertake organised activities. Executive functioning impairments become most evident in the most complex of human conscious activity, or those activities of higher problem solving, reasoning, abstraction and social interaction (Zillmer \& Spiers 2001). These impairments cause many difficulties in daily life (Cazalis et al. 2001; Mazaux et al. 1997).

Further complicating the picture after TBI is the post-concussion syndrome (PCS), which refers to a symptom complex experienced by many patients after TBI, regardless of severity. PCS comprises various symptoms, including cognitive and somatic symptoms. The cognitive symptoms of PCS include attention, concentration and memory problems, while somatic symptoms include fatigue (Jagoda \& Riggio 2005). Patients with PCS perform more poorly on neuropsychological assessment tests than TBI patients without PCS and thus might have more cognitive impairments than the latter group (Bohnen et al. 1995)

It is pertinent for rehabilitation and assessment (including medicolegal assessment) to note that PCS symptoms are not specific to brain-injured patients and can occur in people who do not have a history of a brain injury, or medical or psychiatric problems. People with no history of head injury endorse relatively high base rates of PCS symptoms, such as fatigue, poor concentration, dysexecutive problems and forgetfulness (Chan 2001). Wang, Chan and Deng (2006) demonstrated that the base rate of PCS symptoms in a group of healthy university students was relatively high and that PCS is not related to neuropsychological functions in normal people. There was no difference in the performance of neuropsychological functions between healthy people with PCS and those without PCS. Therefore, it would be problematic to assume uncritically that these self-reported, non-specific symptoms are causally related to brain injury (Iverson \& Lange 2003).

\section{Trends from available literature}

Many studies have reported complaints of fatigue after TBI; however, few have investigated the mechanisms and implications of fatigue (Belmont et al. 2006). Fatigue has implications for rehabilitative efforts and assessment, as it affects executive functions. The implications of fatigue on efficient and effective cognitive functioning are that rehabilitation programmes should rotate the time of day that individuals receive their therapies. For example, neuropsychological rehabilitation sessions should not always be in the afternoons, because patients would not benefit as much as when the sessions were in the mornings on some days. In addition, it is important for therapists to take note of the time of day of the assessment and/or therapy session so as to interpret the individual's functioning and improvements more accurately. Importantly, a fatigued state may approximate an average day's functioning of the individual more closely than a well-rested state. Fatigue during testing may give a more realistic picture of real-world functioning. Nonetheless, assessments performed while patients are not fatigued, such as early in the morning, provide information on their functioning under optimal conditions. Under these conditions, standardised conclusions about their deficits can be reached and generalisations to other contexts can be made. The question arises as to whether certain executive functions, including the ability to hold information in mind, cognitive flexibility, inductive reasoning, attentional capacity and conceptual abilities, are free from the effects of fatigue. It was also queried whether these effects vary between those with and without TBI, so as to infer whether fatigue is a factor to indeed consider in rehabilitation efforts.

\section{Research objectives}

This study examined the impact of fatigue on the executive control of behaviour in an organically compromised population. It was an attempt to answer the question as to whether fatigue, as measured by a subjective questionnaire, negatively impacts on executive control. Executive control refers to the ability to sustain attentional capacity, as required to regulate perceptual and motor processes in order to facilitate the inductive reasoning needed to respond in an adaptive way to changing task demands (Baddeley \& Logie 1999, as cited in Van der Linden, Frese \& Sonnentag 2003). Executive control was operationalised in this study as decreased, cognitive flexibility and increased perseveration, as measured by the WCST.

\section{The following research hypotheses were addressed:}

- Mental fatigue is associated with reduced cognitive flexibility, as operationalised by increased perseveration.

- Mental fatigue is associated with reduced inductive reasoning, as operationalised by a lower number of card sorts.

- Mental fatigue is associated with reduced conceptual abilities, as operationalised by increased non-perseverative errors.

\section{The potential added value of the study}

There were several reasons for conducting this research. There are only a few studies that have explicitly investigated the effects of mental fatigue from an executive control perspective (Van der Linden, Frese \& Meijman 2003). Many studies have reported complaints of fatigue after TBI, regardless of severity, however, few have formally investigated the mechanisms and implications of fatigue on cognitive functioning (Belmont $e t$ al. 2006).

Of all severities, fatigue after TBI is functionally constraining in daily life and impacts on the formal rehabilitation process adversely. Furthermore, fatigue is an important indicator of the responsiveness of patients to medical intervention (Lee, Hicks \& Nino-Murcia 1991). In addition, fatigue impacts negatively on the efficacy of interventions, including rehabilitation. Thus, successful physical and cognitive rehabilitation depends on the patients being in the correct frame of mind. Importantly, fatigue does not seem to be significantly related to the severity of injury or to the time that has elapsed since injury (Belmont et al. 2006). It is vital to understand fatigue in the context of rehabilitative interventions, as well as its impacts in this context and this understanding would lead to the increased efficacy of rehabilitative efforts.

Fatigue has been associated with placing restrictions on an uncompromised return to the workplace or to school in individuals with TBI. It is thought to affect work or school performance, learning and memory. Thus, fatigue affects everyday functioning and for this reason, individuals may need some form of compensated work, tailored work requirements and fewer demands and responsibilities, supervision and/or a structured programme to enable them to work efficiently.

Fatigue also has implications for assessment and may affect cognitive functions differentially; it may impact on executive functions to a different degree than other cognitive functions. Thus, fatigue may impact on the results of neuropsychological tests differentially. This needs to be borne in mind, particularly 
TABLE 1

Biographical information of participants in the traumatic brain injury (TBI) sample

\begin{tabular}{lcccccc}
\hline Group & \multicolumn{5}{c}{ Mean } \\
\cline { 2 - 6 } & Age (years) & Number of years of education & Lowest GCS score (115) & Coma duration (days) & PTA duration (days) & Time since injury (months) \\
\hline TBI fatigue group & $32.93(8.04)$ & $12.2(1.42)$ & $8.6(3.83)$ & $8.54(17.99)$ & $40.07(33.86)$ & $38.13(19.50)$ \\
TBI non-fatigue group & $30.93(8.82)$ & $12.53(1.30)$ & $8.71(3.27)$ & $8.94(16.39)$ & $33.53(30.94)$ & $32.8(16.38)$ \\
\hline
\end{tabular}

Standard deviations are in parentheses.

GCS, Glasgow Coma Scale; PTA, post-traumatic amnesia.

when evaluation is imperative to a medicolegal claim. Importantly, a fatigued state may more closely approximate an average day's functioning of the individual than a wellrested state. Fatigue during testing may give a more realistic picture of real-world functioning, which would result in a more accurate estimate of appropriate compensation. Nonetheless, cognitive testing while patients are not fatigued, such as early in the morning, provides information on their functioning under optimal conditions. Under these conditions, standardised conclusions about their deficits can be reached and generalisations to other contexts can be made.

\section{RESEARCH METHOD AND DESIGN}

\section{Research approach}

This research approach was a combination archival and quasiexperimental, ex-post facto design (Rosnow \& Rosenthal 1996). An analysis of records from patients with moderate to severe TBI was undertaken. The assessments included both the selected measure of executive function and a measure of fatigue as part of a full neuropsychological battery. The records were categorised into fatigue versus non-fatigue conditions based on the time of administration of the relevant measure of executive function. A comparison group of volunteers that did not have a history of TBI were assigned to a fatigued group or to a nonfatigued group, thereby complying with a quasi-experimental research design (Rosnow \& Rosenthal 1996). In this study, the independent variables were fatigue and TBI and the dependent variables were cognitive flexibility, inductive reasoning and conceptual abilities.

\section{Research population and sampling}

Participants in both the TBI and non-TBI groups were all firstlanguage English-speaking individuals in order to eliminate the possible effects of socio-cultural factors on results. All participants had at least 12 years of formal education and were right-handed, so as to exclude the possible confounder of differing hemispheric dominance. Participants were matched as far as possible in terms of age, because elderly people, over approximately 75 years of age, evidence reduced performance on tests of cognitive functioning, including the WCST.

The TBI group consisted of 30 clients having undergone a neuropsychological assessment, which followed the incurring of moderate to severe TBI that had occurred in the last 5 years, but more than 6 months ago. Glasgow Coma Scale (GCS) scores from the first $48 \mathrm{~h}$ to $72 \mathrm{~h}$ post-injury were used to establish injury severity clearly (Lezak, Howieson \& Loring 2004), within the score range of 3 to 12 . The first 30 participants that met the inclusion criteria were selected (see Table 1).

All efforts were made to select 30 age-matched and educationally matched participants for the comparison group. Despite the

\section{TABLE 2}

Biographical information of participants in the non-traumatic brain injury (non-TBI) sample

\begin{tabular}{lcc} 
& \multicolumn{2}{c}{ injury (non-TBI) sample } \\
\cline { 2 - 3 } Group & \multicolumn{2}{c}{ Mean } \\
\hline Non-TBI fatigue & $27.07(9.43)$ & Years of education \\
Non-TBI non-fatigue & $27.27(9.02)$ & $15.33(1.76)$ \\
\hline Standard deviations are in parentheses.
\end{tabular}

authors' efforts, the comparison group was significantly younger $(p=0.03)$ and better educated $(p=0.009)$ than the TBI group. These non-TBI volunteers were assessed using the same protocol as the above-mentioned TBI group. None of these participants had a history of head injury or neurological illness and were obtained through purposive sampling of university students and the immediate community (see Table 2).

Exclusion criteria from the TBI sample included the presence of an aphasic disorder and/or a motor deficit of the dominant upper limb, which may have hampered performance on the verbal and the pen-and-paper tasks respectively. Patients with previous neurological or psychiatric disease, including major illnesses, anxiety, depression, sleep disorders, or with known substance abuse disorders, were also excluded. This was done to exclude possible confounding variables that may have had an impact on subjective fatigue. Furthermore, mild TBI individuals were excluded, because most patients with mild TBI recover within weeks to months after injury, especially if there are no complications, with only $15 \%$ of patients evidencing disability at 1 year post-injury (Alexander 1995).

Participants in the TBI group were tested individually in a clinical setting in sessions that lasted approximately $3 \mathrm{~h}$ ( $2 \mathrm{hfor}$ the testing and $1 \mathrm{~h}$ for the clinical interview). Results from patients who were tested by the same assessor were selected to eliminate inter-rater differences. The assessments all occurred in the mornings to control for possible fatigue associated with testing in the afternoon.

\section{Research measuring instruments}

The WCST is a standard clinical measure of executive functioning, which requires cognitive flexibility, problem solving and the use of feedback to guide behaviour (Heaton et al. 1993) and is regarded as a sensitive measure of behavioural rigidity (Heaton 1981). In the WCST (Berg 1948; Grant \& Berg 1948), participants have to discover how to sort cards that hold geometrical figures. However, because no detailed instructions are given, participants must discover the sorting rules independently through systematic exploration. In the WCST, such exploration is supported by feedback after each trial. Once participants discover the currently active sorting rule (which in the WCST is operationalised as 10 correct consecutive responses), the rule changes without notice. Subsequently, the participants must use feedback to observe or notice that the sorting rule has changed and they have to discover the new sorting rule (Van der Linden, Frese \& Meijman 2003).

It is difficult to assess fatigue with objective tests: Most assessment scales of fatigue rely on subjective self-reports. 'Instantaneous' fatigue is assessed by the VAS-F (Visual Analogue Scale for Fatigue), which comprises 18 items, 13 measuring the intensity of fatigue and 5 measuring the intensity of energy (Lee et al. 1991). Participants were required to read each statement and respond by placing an ' $\mathrm{X}$ ' along a $100-\mathrm{mm}$ line in a position that they felt best represented their current state. A total fatigue score on this measure was obtained and this value was used in the analyses (Lee et al. 1991).

\section{Research procedure}

The standard neuropsychological fatigue test battery included (in order) the WAIS-R Digit Span Test (Wechsler 1997), the 
UCLA-AVLT (Schmidt 1996), the WMS-R Logical Memory Test (Wechsler 1987), the Trail Making Test (War Department 1944), the Digit Symbol Substitution Subtest from the WAIS-R (Wechsler 1981), the Taylor Complex Figure Memory Test (Duley et al. 1992), the WAIS-R Arithmetic Test (Wechsler 1981), the WAIS-R Block Design Test (Wechsler 1981), the Stroop ColourWord Interference Test (Golden 1978), the Visual Analogue Scale for Fatigue (Lee et al. 1991), the WCST (Berg 1948; Grant \& Berg 1948) and a repeat of the Digit Span Test.

The standard non-fatigue test battery - for the participants who completed the measures of interest at the beginning of the battery, prior to the assumed onset of fatigue - included (in order) the WAIS-R Digit Span Test, the Visual Analogue Scale for Fatigue, the WCST, the UCLA-AVLT, the WMS-R Logical Memory Test, the Trail Making Test, the Digit Symbol Substitution Subtest, the Taylor Complex Figure Memory Test, the WAIS-R Arithmetic Test, the WAIS-R Block Design Test, the Stroop Colour-Word Interference Test and a repeat of the Digit Span Test.

For the TBI participants, the clinical interview was conducted before the testing session. Participants in the non-TBI group were only required to complete the standard neuropsychological battery in a 2-h testing session and did not have to complete an interview.

Participants in the TBI group were assigned to a fatigue $(n=15)$ or a non-fatigue condition $(n=15)$ based on the suitability of the assessment schedule adhered to at the time of their assessment. Participants in the non-TBI group were randomly assigned to a fatigue $(n=15)$ or a non-fatigue condition $(n=15)$. Fatigue was induced through working on cognitively demanding tasks similar to those used in clinical assessment, for approximately $2 \mathrm{~h}$. Only the neuropsychological tests of interest were scored.

\section{Data collection and statistical analysis}

The raw data were subjected to Kolmogorov and Levene's tests to determine whether the data were normally distributed and whether there was homogeneity of variance. This was found to be the case; therefore, parametric tests were deemed appropriate (Howell 2004).

A 2 (TBI vs. non-TBI) x 2 (fatigued vs. non-fatigued) mixed model analysis of variance (ANOVA) was conducted with each dependent variable. The dependent variables included the number of card sorts, the percentage of perseverative errors, the percentage of non-perseverative errors and the number of set maintenance failures. The first two factors are between subject factors and the third factor is a repeated (or within-subject) factor. This served to investigate the effect of the independent variable of reported fatigue (total fatigue score on the VAS-F) on the dependent variables, the effect of the independent variable of TBI on the dependent variables and whether there was an interaction effect.

\section{RESULTS}

Means (M) and standard deviations (S) were calculated separately for the four groups for each of the variables of interest (see Table 3): Mean fatigue, mean number of sorts, mean percentage of perseveration and mean percentage of nonperseverative errors.

A two-way ANOVA was conducted with each dependent variable. The two independent variables were TBI vs. no TBI and fatigue vs. no fatigue. The dependent variables included the fatigue score, the number of card sorts, the percentage of perseverative errors and the percentage of non-perseverative errors.

In order to investigate whether mental fatigue was associated with reduced inductive reasoning, the dependent variable, number of sorts, was examined. The mean number of sorts was significant between individuals with TBI and individuals without TBI $(\mathrm{F}=9.63 ; p=0.003)$. The number of sorts was not significantly different between fatigued and non-fatigued individuals $(\mathrm{F}=0.01 ; p=0.92)$. There was no interaction effect between TBI and fatigue on the number of sorts $(\mathrm{F}=1.14 ; p=$ 0.29).

Mental fatigue did not significantly impact on inductive reasoning, as operationalised by the mean number of sorts. However, there was a non-significant trend in the data that indicated a tendency towards less inductive reasoning when fatigued in both TBI and non-TBI individuals. Furthermore, individuals with TBI evidenced significantly reduced inductive reasoning compared to individuals without TBI. Given the vast literature available on the construct validity of the WCST (Heaton 1981; Kimberg \& Farah 1993; Milner 1963; Norman \& Shallice 1986), the difference in performance between the TBI and nonTBI group on this variable is likely to be a factor of compromise of the brain. It is unlikely that the difference in performance is a factor of level of intelligence, as might be implied by the mean level of education in the two groups - the reason being that education has been found to affect performance only to a small degree in previous research (Boone et al. 1993).

In order to investigate whether mental fatigue was associated with reduced cognitive flexibility, the dependent variable, percentage of perseveration, was examined. The mean percentage of perseverative errors was significant between individuals with TBI and individuals without TBI $(\mathrm{F}=14.58 ; p$ $=0.0003)$. That is, individuals with TBI performed significantly differently from individuals without TBI. The percentage of perseverative errors was not significantly different between fatigued and non-fatigued individuals $(\mathrm{F}=0.82 ; p=0.37)$.

Fatigue was expected to coincide with increased perseveration. Mental fatigue did not significantly impact on cognitive flexibility, as operationalised by the percentage of perseverative errors. However, there was a trend for increased perseveration in TBI individuals.

Individuals with TBI evidenced significantly reduced cognitive flexibility compared to individuals without TBI - the mean percentage of perseverative errors was much higher for TBI individuals than for individuals without TBI. Furthermore, there was an interaction effect, whereby fatigue impacted on

TABLE 3

Means of the variables of interest of the experimental tasks in traumatic brain injury (TBI) and non-traumatic brain injury (non-TBI) groups

\begin{tabular}{|c|c|c|c|c|}
\hline \multirow[t]{2}{*}{ Experimental Tests } & \multicolumn{2}{|l|}{ TBI } & \multicolumn{2}{|c|}{ Non-TBI } \\
\hline & Non-fatigued group $(n=15)$ & Fatigued group $(n=15)$ & Non-fatigued group $(n=15)$ & Fatigued group $(n=15)$ \\
\hline \multicolumn{5}{|l|}{ VAS-F } \\
\hline Fatigue scale & $0.48(0.25)$ & $0.51(0.25)$ & $0.45(0.22)$ & $0.53(0.28)$ \\
\hline \multicolumn{5}{|l|}{ WCST } \\
\hline Number of sorts & $5.07(2.37)$ & $4.20(2.11)$ & $6.20(2.31)$ & $6.80(2.83)$ \\
\hline Percentage of perseveration & $20.79(8.63)$ & $30.07(14.79)$ & $16.87(9.53)$ & $13.40(8.99)$ \\
\hline Percentage of non- perseverative errors & $23.14(11.29)$ & $21.20(8.87)$ & $17.60(5.72)$ & $16.53(6.06)$ \\
\hline
\end{tabular}


cognitive flexibility to a greater extent in TBI individuals than those without TBI.

In order to investigate whether mental fatigue was associated with reduced conceptual abilities, the dependent variable, percentage of non-perseverative errors, was examined. The percentage of non-perseverative errors was significantly different between individuals with TBI and individuals without TBI $(\mathrm{F}=5.35 ; p=0.024)$. That is, individuals with TBI performed significantly differently from individuals without TBI. The percentage of non-perseverative errors was not significantly different between fatigued and non-fatigued individuals $(\mathrm{F}=$ $0.38 ; p=0.54)$. There was no interaction effect between TBI and fatigue on the percentage of non-perseverative errors $(\mathrm{F}=0.1 ; p$ $=0.91$ ).

Mental fatigue did not impact significantly on conceptual abilities, as operationalised by the percentage of non-perseverative errors. Unexpectedly, there was a trend for both individuals with and without TBI towards fewer non-perseverative errors when fatigued. Individuals with TBI evidenced significantly reduced conceptual abilities compared to individuals without TBI. As previously discussed, the difference in performance between the TBI and non-TBI group on this variable is more likely to be a factor of compromise of the brain than a factor of level of education in the two groups.

The mean fatigue score on the VAS-F was not significantly different between individuals with TBI and individuals without TBI $(\mathrm{F}=0.44 ; p=0.51)$. That is, individuals with TBI did not score significantly differently from individuals without TBI. The mean fatigue score was not significantly different between fatigued and non-fatigued individuals $(\mathrm{F}=0.73 ; p=0.39)$. There was no interaction effect between TBI and fatigue on the mean fatigue score $(\mathrm{F}=0.12 ; p=0.73)$

This analysis suggests that fatigue increased in both individuals with TBI and those without TBI in all of the groups (the increase was not significantly different). The fatigue manipulation did not have a significantly greater impact on non-TBI than on TBI individuals. Nonetheless, based on the trends evident in the data, this would suggest that the fatigue manipulation was successful in increasing participants' level of subjective fatigue after working on cognitively demanding tasks for approximately $2 \mathrm{~h}$.

\section{Validity and reliability}

The WCST has been shown to be reliable and valid in many different contexts and it has been extensively studied in many contexts. Validity research has suggested that patients with frontal lobe damage and assumed consequent impairments of executive functioning, may perform worse on the WCST than do patients with focal brain damage in non-frontal regions. The focal frontal lobe damage groups tend to achieve lower numbers of category shifts and show higher levels of perseverative errors than do non-frontal groups (Anderson et al. 1991). These results suggest good criterion-related validity. Reliability research has yielded high inter-scorer reliabilities with reliability coefficients > 0.94 (Milner 1963)

As opposed to one-item measures, the VAS-F is a more stable estimate of fatigue. Lee et al. (1991) consider it to be valid and reliable in both non-pathologic populations and pathologic populations. A significant positive correlation has been found between the FIS and the 13 fatigue items of the VAS-F, as well as a significant negative correlation between the five energy items of the VAS-F and the other scales (LaChapelle \& Finlayson 1998).

\section{ETHICAL CONSIDERATIONS}

The data for the participants with TBI were from cases that had already been tested as part of an ongoing clinical practice. These individuals had signed consent forms, granting their permission to use the data for research purposes. The data for the contrast group consisted of volunteer participants who were given information sheets and were required to sign consent forms prior to their evaluations, giving their permission to use their data for research purposes.

All information that may identify participants was removed; thus, confidentiality was ensured. Unavoidably, the researcher knows the identity of the participants and anonymity was not possible. There were no risks involved for the participants, as both the clinical interview and the neuropsychological tests that were used are deemed to be non-invasive, low-risk instruments that are not likely to evoke psychological disturbance. Ethical clearance was first granted from formal structures within the University of the Witwatersrand (protocol number MDISS/08/001 1H)

\section{DISCUSSION}

\section{Main objective}

The present study examined the impact of fatigue on the executive control of behaviour in a TBI and non-TBI population. It was an attempt to answer the question of whether fatigue impacts on executive control (the ability to sustain attentional capacity as required to regulate perceptual and motor processes in order to facilitate the inductive reasoning needed to respond in an adaptive way to changing task demands) (Baddeley \& Logie 1999, as cited in Van der Linden Frese \& Sonnentag 2003). Executive control was operationalised as decreased cognitive flexibility and increased perseveration as measured by the WCST.

\section{Importance of the study}

Of all severities, fatigue after TBI is constraining in daily life, adversely impacts on the rehabilitation process and places restrictions on an uncompromised return to the workplace. Fatigue is an important indicator of the responsiveness of patients to medical intervention (Lee et al. 1991). In addition, it impacts negatively on the efficacy of interventions such as cognitive rehabilitation. Thus, successful rehabilitation depends on the patients being in the 'correct frame of mind'. Importantly, fatigue does not seem to be significantly related to the severity of injury or to time since injury (Belmont et al. 2006).

Summary of results in relation to hypotheses

Fatigue was expected to coincide with a lower number of discovered sorting rules on the WCST and reduced inductive reasoning. The results of this study showed that there was a trend towards reduced inductive reasoning when the participants were fatigued. This trend held true for both TBI and non-TBI individuals.

In the WCST, lowered cognitive flexibility in task behaviour is operationalised as perseveration. Fatigue was expected to coincide with increased perseveration and reduced cognitive flexibility. The results of this study showed that there was a trend towards reduced cognitive flexibility and increased perseveration in fatigued TBI individuals. This trend was not consistent in non-TBI individuals. Thus, fatigue impacted on cognitive flexibility to a greater extent in TBI individuals than in individuals that were not organically compromised.

A further expectation of this study was that fatigue would result in reduced conceptual abilities; that it would hamper the conceptual abilities of participants. In this study, mental fatigue did not significantly impact on conceptual abilities and in contrast to expectations, there was a trend towards fewer nonperseverative errors for both individuals with and without TBI when fatigued.

\section{Linking the findings to available literature}

Consistent with expectations and further confirming the construct validity of the WCST, individuals with TBI performed significantly worse than non-TBI individuals on all of the 
aspects of this measure that were examined. The individuals that had sustained TBI did not suffer any focal frontal damage, as confirmed by collateral information and brain scans. Nevertheless, their performance on this measure was truncated compared to healthy individuals. All of the TBI individuals had diffuse axonal injury. It may be the case that the scattered white matter damage reduced the efficacy of information processing in the frontal lobes of the brain, leading to impoverished performance on this sensitive and specific measure (Van der Linden, Frese \& Meijman 2003).

Individuals with TBI evidenced significantly reduced inductive reasoning compared to individuals without TBI. Individuals with TBI also showed significantly reduced cognitive flexibility compared to individuals without TBI. Thus, the individuals with TBI perseverated in their answers and had substantial difficulty relinquishing a response set when it was no longer appropriate, compared to individuals with no history of TBI. In addition individuals with TBI showed significantly reduced conceptual abilities compared to individuals without TBI.

\section{Fatigue manipulation}

In order to measure subjective levels of fatigue in the participants, a self-report, visual analogue scale of fatigue was used. Non-fatigued individuals in both the TBI and non-TBI groups completed the scale prior to the fatigue manipulation. Fatigued individuals in both TBI and non-TBI groups completed the scale after the fatigue manipulation. Levels of fatigue were subjectively higher in all individuals after the $2 \mathrm{~h}$ of working on cognitively demanding tasks, suggesting that the testing was fatiguing. However, individuals with TBI did not score significantly differently from individuals without TBI on the subjective rating scale of fatigue. This analysis shows that manipulation was successful in increasing participants' level of subjective fatigue after approximately $2 \mathrm{~h}$ of working on cognitively demanding tasks, irrespective of organic status, but that TBI individuals did not feel that they were more fatigued than non-TBI individuals.

\section{The effects of fatigue on executive functioning}

This study specifically examined whether mental fatigue coincides with compromised executive control. Executive control depends on the ability to hold goals and goal-related information active in mind so that they can exert their influence on the selection of actions (Kimberg \& Farah 1993). The reduced performance on the WCST of fatigued participants appeared to be caused by a difficulty to uphold sufficient levels of executive control during the task. In real-world situations, fatigued individuals are less likely to be able to select appropriate actions based on goal-related information, as this information is not held sufficiently active in mind. Thus, decisions are likely to be driven by emotion and/or ease or resolution.

Fatigue was expected to coincide with a lower number of discovered sorting rules on the WCST and reduced inductive reasoning. The results of this study showed that there was a trend towards reduced inductive reasoning when the participants were fatigued. This trend held true for both TBI and non-TBI individuals. Thus, fatigue impacted negatively on the capacity for inductive reasoning for both organically TBI and non-TBI individuals. In real life, when encountering a novel problem, fatigued individuals are less likely to be able to reflect on knowledge of a similar situation and use this knowledge in decision making.

In the WCST, lowered cognitive flexibility in task behaviour is operationalised as perseveration. Fatiguewasexpected tocoincide with increased perseveration and reduced cognitive flexibility. It was expected that, despite continual feedback that the manner in which the participant was responding was incorrect, these participants would continue to respond in this mal-adaptive, perseverative manner. The results of this study showed that there was a trend towards reduced cognitive flexibility and increased perseveration in fatigued TBI individuals. Compared to non-fatigued TBI participants, fatigued TBI participants made more perseverative errors on the WCST, which implies that they repeatedly tried to sort cards according to a rule that had already proved faulty in earlier sorting attempts (Van der Linden, Frese \& Meijman 2003). Fatigued TBI participants showed more performance deficits than non-fatigued participants on tasks that required the flexible generation and testing of hypotheses. This trend was not consistent in non-TBI individuals. Thus, fatigue impacted on cognitive flexibility to a greater extent in TBI individuals than in individuals that were not organically compromised, even when controlling for short-term memory. The implications of this result are that fatigued TBI participants are likely to respond to situations based on actions that have driven preceding behaviours. This perseverative behaviour is unlikely to be modified on the basis of feedback that the manner of response is inappropriate.

The goal-activation perspective states that during perseveration the representations of task goals themselves may be unaffected, yet their activation may be too low to exert influence on the selection of actions (Duncan et al. 1996). This means that the TBI participants may perseverate even if they are aware that their current actions are no longer appropriate. Although this study did not examine the extent to which fatigued participants were aware of the inappropriateness of their actions during perseveration, it is assumed that they perceived the feedback after a sorting attempt (Heaton 1981). Specifically, after each trial/card selection, feedback was provided to the participant, which stayed on the screen until participants continued with the next trial. Thus, even the fatigued TBI participants must have noticed that their sorting actions had not been successful; nevertheless, they evidenced perseveration.

A further expectation of this research was that fatigue would result in hampering the conceptual abilities of participants. In this study, mental fatigue did not significantly impact on conceptual abilities: both individuals with and without TBI showed a trend towards fewer non-perseverative errors when fatigued. An explanation for this unexpected result may be that the errors that were made were perseverative and not nonperseverative, in nature. Furthermore, fatigued participants did not show a trend towards an increased number of nonperseverative errors compared to non-fatigued participants. This implies that perseverative errors were the most reliable effects of fatigue.

Working on cognitively demanding tasks for a considerable time often leads to mental fatigue, which impacts negatively on task performance. The way in which the cognitive control of behaviour changes under fatigue is unclear. Some researchers propose that mental fatigue affects those control processes that are involved in the organisation of actions and that play a major role in deliberate and goal-directed behaviour; this is the 'control view' of fatigue (Bartlett 1943). Another relevant finding in fatigue research that supports the 'control view' is that performance on simple or well-learned tasks, which can be executed in a more or less automatic way, can be upheld over long periods of time, after sleep deprivation, or after mentally demanding activities. On the other hand, complex tasks that require the deliberate control of behaviour are generally difficult to perform under such circumstances (Broadbent 1979).

These typical effects on different levels of information processing are found in several fatigue studies and the specific disorganisation of behaviour that tends to occur under fatigue suggests that mental fatigue is mainly characterised by the deterioration of executive control (Baddeley \& Logie 1999, as cited in Van der Linden, Frese \& Sonnentag 2003). However, the results of this study suggest that even more automatic processes, such as the ability to hold information in mind, were affected by fatigue. Fatigue appears to hamper the efficacy of global cognitive functions, not only those functions associated with executive control. 


\section{LIMITATIONS OF THE STUDY}

This study made use of relatively small sample sizes. There were 15 participants in each of the four groups. Future research may be improved by using larger sample sizes in order to increase the strength of the investigation (Howell 2004). The trends that were evident in this research may become significant when the sample sizes are increased.

Both TBI and non-TBI individuals were assessed in the morning hours of the day and all participants completed the Digit Span Test at the beginning of the battery. Importantly, both groups performed equally on this test. This implies that the clinical interview that the TBI participants were subjected to prior to the assessment did not bias or disadvantage the group on this measure and therefore is unlikely to have affected the overall results. In addition, the non-TBI participants were required to provide demographic data - they were also subjected to a short interview prior to the assessment. Nevertheless, it is plausible that the TBI participants experienced fatigue as a result of the longer interview and therefore were somewhat disadvantaged from the beginning. Furthermore, it is possible that as a result of this, their performance deteriorated further after $2 \mathrm{~h}$ of testing. Another consideration is that, even though the testing was conducted in the morning, it was impossible to control what they had done prior to the assessment and how well they had slept the night before.

This study was restricted to an examination of moderate and severe TBI participants, with no emphasis being placed on individuals with mild head injuries. Future investigations should include participants with mild TBI in order to better understand the mechanisms and implications of fatigue in this group of people.

The role that motivation plays in cognitive tasks under fatigue was not investigated. Executive control strongly overlaps with motivation in the sense that adequate control of behaviour is only exerted when some importance is assigned to task goals (Monsell \& Driver 2000). For example, people with impaired executive control seem to lack the 'drive' to engage in selfdirected behaviour and to initiate actions (Duncan et al. 1996). Such lack of drive or action initiation is also typical for fatigued people (Meijman 2000). For this reason, future research should investigate the role of motivation in cognition under fatigued conditions.

The extent to which fatigued participants were aware of the inappropriateness of their actions during perseveration was not examined; it was assumed that they perceived the feedback after a sorting attempt. Thus, even the fatigued TBI participants must have noticed that their sorting actions had not been successful; nevertheless, they showed perseveration. Future research could examine the insight of TBI individuals into their performance.

\section{Suggestions for future research}

Future research could investigate the differential effects of neurological disease or damage known to influence executive control on WCST performance, including perseveration. In particular, there are theories on the biological substrates of executive control which state that dopamine plays a major role in the activation (stability) of goal representations (Braver $e t$ al. 2001). Moreover, dopamine activity has been associated with intrinsic motivation (Tucker \& Williamson 1984). Both of these concepts are strongly related to mental fatigue.

It is generally known that coffee intake, which enhances dopamine release, reduces both the subjective and objective effects of mental fatigue (Lorist 1998). This idea poses a direction for future studies on the relationship between mental fatigue and executive control.

\section{CONCLUSION AND RECOMMENDATIONS}

This study showed that fatigue impacts negatively on inductive reasoning in individuals with no history of TBI. This trend also held true for individuals with TBI - fatigue, a somatic symptom of PCS, is related to neuropsychological functioning in TBI individuals. Thus, fatigue has substantial implications for optimal cognitive functioning, even in non-TBI individuals that are better equipped cognitively to compensate for these effects.

The results indicate that individuals with TBI perform more poorly on neuropsychological measures of executive functioning than individuals with no history of head injury. This finding has the implication that TBI individuals will not be able to compensate as efficiently for affected cognitive functions as healthy individuals when they are fatigued.

In line with expectations, trends show that fatigue results in reduced inductive reasoning capacities for both TBI and healthy participants. In daily life, not only TBI individuals, but also healthy individuals, show reduced propensity towards analytical thinking when fatigued. This was echoed in the results of this study. Fatigue was also shown to result in greater levels of perseveration in the TBI group. This implies that the level of exerted executive control was reduced under fatigue, that goal activation was reduced under fatigue and that there was reduced integration of feedback under fatigued conditions. Perseveration appears to be a reliable effect of fatigue in TBI individuals.

In contrast to expectations, fatigue impacted negatively on the ability to hold information active in mind, which is an automatic cognitive process, in both TBI and healthy individuals and thus, it appears to affect global cognitive functions and not only the cognitive processes of executive control.

This research supports the overall view that compromised executive control underlies behavioural manifestations of mental fatigue. There are several studies showing that fatigue seems to affect high-level cognitive processes (Hockey 1997; Holding 1983; Sanders 1998). This study approaches fatigue from an executive control perspective, which has important implications. Compromised executive control under fatigue does not imply that certain basic cognitive processes can no longer be executed at all and it does not imply that cognitive processes are fundamentally changed under fatigue. From a goal-activation perspective, compromised executive control under fatigue implies a reduced probability that actions will be guided by task goals or by changing task context (Braver et al. 2001). Subsequently, there will be an increased tendency for more automatic regulatory processes to guide action selection, even when this is inappropriate. Lapses in the exertion of executive control may be responsible for the typical slips of action and intrusion errors that are often found in fatigued people (Hockey 1997; Holding 1983; Sanders 1998).

\section{ACKNOWLEDGEMENT}

This research was conducted in fulfilment of a Master of Science (Psychology) degree at the University of the Witwatersrand.

\section{REFERENCES}

Aaronson, L., Teel, C., Cassmeyer, V., Neuberger, G., Pallikkathayil, L. \& Pierce, J., 1999, 'Defining and measuring fatigue', Image: The Journal of Nursing Scholarship 31, 45-50.

Alexander, M.P., 1995, 'Mild traumatic brain injury: Pathophysiology, natural history, and clinical management', Neurology 45, 1253-1260.

Anderson, S., Damasio, H., Jones, R. \& Tranel, D., 1991, 'Wisconsin Card Sorting Test performance as a measure of frontal lobe damage', Journal of Clinical and Experimental Neuropsychology 13, 99-122.

Bartlett, F., 1943, 'Fatigue following highly skilled work', Proceedings of the Royal Society of London. Series B: Biological Sciences 131(864), 247-257.

Belmont, A., Agar, N., Hugeron, C., Gallais, B. \& Azouvi, P., 2006, 'Fatigue and traumatic brain injury', Annals of Physical and Rehabilitation Medicine 49(6), 370-374. 
Berg, E., 1948, 'A simple objective technique for measuring flexibility in thinking', The Journal of General Psychology, 39, 15-22, viewed 2008, from http://www.ncbi.lm.nih.gov/ pubmed/ 1889466

Bohnen, N., Wijnen, G., Twijnstra, A., Van Zutphen, W. \& Jolles, J., 1995, 'The constellation of late post-traumatic symptoms of mild head injury patients', Neurorehabilitation and Neural Repair 9(1), 33-39, viewed 2008, from http://www.nnr. sagepub.com/cgi/content

Boone, K., Ghaffarian, S., Lesser, I., Hill-Gutierrez, E. \& Berman N., 1993, 'Wisconsin Card Sorting Test performance in healthy, older adults: Relationship to age, sex, education and $\mathrm{IQ}^{\prime}$, Journal of Clinical Psychology 49, 54-60.

Braver, T., Barch, D., Keys, B., Carter, C., Cohen, J., Kaye, J., 2001, 'Context processing in older adults: Evidence for a theory relating cognitive control to neurobiology in healthy aging' Journal of Experimental Psychology: General 130(4), 746-763.

Broadbent, D., 1979, 'Is a fatigue test now possible?' Ergonomics 22(12), 1277-1290

Cazalis, F., Azouvi, P., Sirigu, A., Agar, N. \& Burnod, Y., 2001 'Script knowledge after severe traumatic brain injury', Journal of the International Neuropsychological Society 7(7), 795-804.

Chan, R., 2001, 'Base rate of postconcussion symptoms among normal people and its neuropsychological correlates', Clinical Rehabilitation 15(3), 266-273.

Duley, J., Wilkins, J., Hamby, S., Hopkins, D., Burwell, R. \& Barry N., 1992, 'Explicit scoring criteria for the Rey-Osterrieth and the Taylor Complex Figures', The Clinical Neuropsychologist 7(1), 29-38.

Duncan, J., Emslie, H., Williams, P., Johnson, R. \& Freer, C., 1996, 'Intelligence and the frontal lobe: The organisation of goaldirected behaviour', Cognitive Psychology 30(3), 257-303.

Golden, C., 1978, Stroop Color and Word Test: A manual for clinical and experimental uses, Skoelting, Chicago, Ill.

Grant, D. \& Berg, E., 1948, 'A behavioural analysis of degree of reinforcement and ease of shifting to new responses in a Weigl-type card sorting problem', Journal of Experimental Psychology 38(4), 404-411.

Heaton, R., 1981, Wisconsin Card Sorting Test Manual, University of Colorado, Odessa.

Heaton, R., Chelune, G., Kay, G., Talley, J. \& Curtis, G., 1993, Wisconsin Card Sorting Test manual: Revised and expanded, Psychological Assessment Resources, Odessa.

Hockey, G.R., 1997, 'Compensatory control in the regulation of human performance under stress and high workload: A cognitive-energetic framework', Biological Psychology 45 , 73-93.

Holding, D., 1983, 'Fatigue', in R. Hockey (ed.), Stress and fatigue in human performance, pp. 145-164, Wiley, Durham.

Howell, D.C., 2004, Fundamental Statistics for the Behavioural Sciences, 5th edn., Brooks/Cole, California.

Iverson, G. \& Lange, R., 2003, 'Examination of postconcussionlike symptoms in a healthy sample', Applied Neuropsychology 10(3), 137-144.

Jagoda, A. \& Riggio, S., 2005, 'Mild traumatic brain injury and the post-concussive syndrome', Emergency Medicine Clinics of North America 18(2), 355-363.

Kimberg, D. \& Farah, M., 1993, 'A unified account of cognitive impairments following frontal lobe damage: The role of working memory in complex organised behaviour', Journal of Experimental Psychology: General 122(4), 411-428.

LaChapelle, D. \& Finlayson, M., 1998, 'An evaluation of subjective and objective measures of fatigue in patients with brain injury and healthy controls', Brain Injury 12(8) 649-659.

Lee, K., Hicks, G. \& Nino-Murcia, G., 1991, 'Validity and reliability of a scale to assess fatigue', Psychiatry Research 36 , 291-298

Lezak, M., Howieson, D.B. \& Loring, D.W., 2004 Neuropsychological Assessment, 4th edn., Oxford University Press, New York.
Lorist, M., 1998, 'Caffeine and information processing in man, in J. Snel \& M. Lorist, (eds.), Nicotine, caffeine, and social drinking: Behaviour and brain function, Harwood Academic Publishers, Amsterdam

Mazaux, J., Masson, F., Levin, H., Alaoui, P., Maurette, P. \& Barat, M., 1997, 'Long-term neuropsychological outcome and loss of social autonomy after traumatic brain injury' , Archives of Physical Medicine and Rehabilitation 78(12), 1316-1320.

Meijman, T., 2000, 'The theory of the stop-emotion: On the functionality of fatigue', in D. Pogorski \& W. Karwowski (eds.), Ergonomics and safety for global business quality and production, pp. 45-50, CIOP, Warsaw.

Milner, B., 1963, 'Effects of different brain lesions on card sorting: The role of the frontal lobes', Archives of Neurology 9(1), 90-100

Monsell, S., \& Driver, J., 2000, 'Control of cognitive processes: Attention and performance, XVIII', The MIT Press, Cambridge.

Norman, D., \& Shallice, T., 1986, 'Attention to action: Willed and automatic control of behaviour', in R. Davidson, G. Swartz \& D. Shapiro (eds.), Consciousness and self-regulation: Advances in theory and research, vol. 4, pp. 1-18, Plenum Press, New York.

Olver, J., Ponsford, J. \& Curran, C., 1996, 'Outcome following traumatic brain injury: A comparison between 2 and 5 years after injury', Brain Injury 10(11), 841-848.

Ponsford, J. \& Kinsella, G., 1992, 'Attentional deficits following severe closed head injury', Journal of Clinical Experimental Neuropsychology 14(5), 822-838.

Rosnow, R. \& Rosenthal, R., 1996, Beginning behavioural research: A conceptual primer, Prentice-Hall, New Jersey.

Sanders, A.F., 1998, Elements of human performance: Reaction processes and attention in human skill, Lawrence Erlbaum, London.

Schmidt, M., 1996, Rey Auditory Verbal Learning Test: A handbook, Western Psychological. Services, Los Angeles.

Smith, D., Meaney, D. \& Shull, W., 2003, 'Diffuse axonal injury in head trauma', Journal of Head Trauma Rehabilitation 18, 307-316.

Tucker, D.M., \& Williamson, P.A., 1984, 'Asymmetric neural control systems in human self-regulation', Psychological Review 91, 185-215.

Van der Linden, D., Frese, M. \& Meijman, T., 2003, 'Mental fatigue and the control of cognitive processes: Effects on perseveration and planning', Acta Psychologica 113, 45-65.

Van der Linden, D., Frese, M. \& Sonnentag, S., 2003, 'The impact of mental fatigue on exploration in a complex computer task: Rigidity and loss of systematic strategies', Human Factors: The Journal of Human Factors and Ergonomics Society 45(3), 483494, viewed 2 March 2008, from doi: 10.1518/hfes.45.3.27256

Van der Naalt, J., Van Zomeren, A., Sluiter, W. \& Minderhoud, J., 1999, 'One year outcome in mild to moderate head injury: The predictive value of acute injury characteristics related to complaints and return to work', Journal of Neurology, Neurosurgery and Psychiatry 66(2), 207-213.

Wang, Y., Chan, R. \& Deng, Y., 2006, 'Examination of postconcussion-like symptoms in healthy university students: Relationships to subjective and objective neuropsychological function performance', Archives of Clinical Neuropsychology 21, 339-347.

War Department, Adjunct General's Office Trail, 1944, Army Individual Test Battery: Manual of direction and scoring, Washington DC.

Wechsler, D., 1981, WAIS-R manual, The Psychological Corporation, New York.

Wechsler, D., 1987, Wechsler Memory Scale: Revised manual, The Psychological Corporation, San Antonio.

Wechsler, D., 1997, Wechsler Adult Intelligence Scale-III, The Psychological Corporation, San Antonio.

Zillmer, E.A. \& Spiers, M.V., 2001, Principles of neuropsychology, Wadsworth/Thomson Learning, California. 